\title{
Understanding Controversy
}

\section{Government Information on Dietary Sustainability}

\author{
Sarah Klimek
}

W

hen the Advisory Report for the 2015 Dietary Guidelines for Americans was released in February 2015, news outlets and other media platforms quickly zeroed in on some of the report's most controversial guidelines. Roughly one week after the report was released, National Public Radio released a news story titled "Will the Dietary Guidelines Consider the Planet? The Fight is On," discussing the heated controversy that was already brewing over a particular recommendation that addressed the topic of environmental sustainability. ${ }^{1}$ This recommendation essentially warned that current dietary patterns in the United States have created serious environmental problems that threaten long-term food security, and therefore the guidelines should not only recommend dietary changes that support human nutrition, but that also support the consumption of more environmentally sustainable foods. ${ }^{2}$ As illustrated in the report's media coverage, this recommendation produced a storm of controversy, particularly on whether issues of environmental sustainability were appropriate inclusions in a report that focused on human health and nutrition. When the final version of the Dietary Guidelines for Americans eventually appeared in December 2015, the sustainability guideline was noticeably absent from the recommendations.

\section{Summary}

While news outlets provided fairly extensive coverage of the arguments held both for and against the inclusion of a sustainability recommendation, they provided fairly little background into the actual issue introduced by the Advisory Report: how dietary choices, from the population level down to the individual level, impact not only human health but also the health of the environment. Yet it appears that the federal government, which is typically a valuable source for information on current social, political, and economic issues, has done little to publish and disseminate resources that explain this issue to the general public. While government agency websites and other resources provide access to information on tangential issues related to agricultural and environmental sustainability, few resources geared specifically toward educating the public on the connection between diet and sustainability exist. Given the important role that government resources can play in educating the public on current issues, this absence of government information has notable limitations on the public's ability to learn about how this issue might affect their lives and the creation of government policy. Fortunately, the growing level of attention that this topic has received, as illustrated both in the advisory report itself and the growth of international resources addressing this topic, provides an exciting opportunity for the creation of new government educational resources. By publishing more information specifically for the general public on the connection between dietary choices and environmental sustainability, the US government would more effectively uphold its role in supporting the public's ability to stay informed of current government issues.

\section{Background to Government Involvement in Sustainability}

Concerns surrounding environmental sustainability have influenced government policy since the conservation movements of the early twentieth century, but the issue was not firmly embedded into federal policy until the creation of the National Environmental Policy Act of 1969. ${ }^{3}$ This act laid out the fundamental goals for a national sustainability policy that would "create and maintain conditions under which man and nature can exist in productive harmony" and established required sustainability regulations for federal agencies. ${ }^{4}$ More specifically, in recognizing "the critical importance of restoring and maintaining environmental quality to the overall welfare and development of man," NEPA set out to address environmental problems created by activities like industrialization and resource exploitation, to mitigate their impact on the quality of the 


\section{DIETARY GUIDELINES PROCESS}

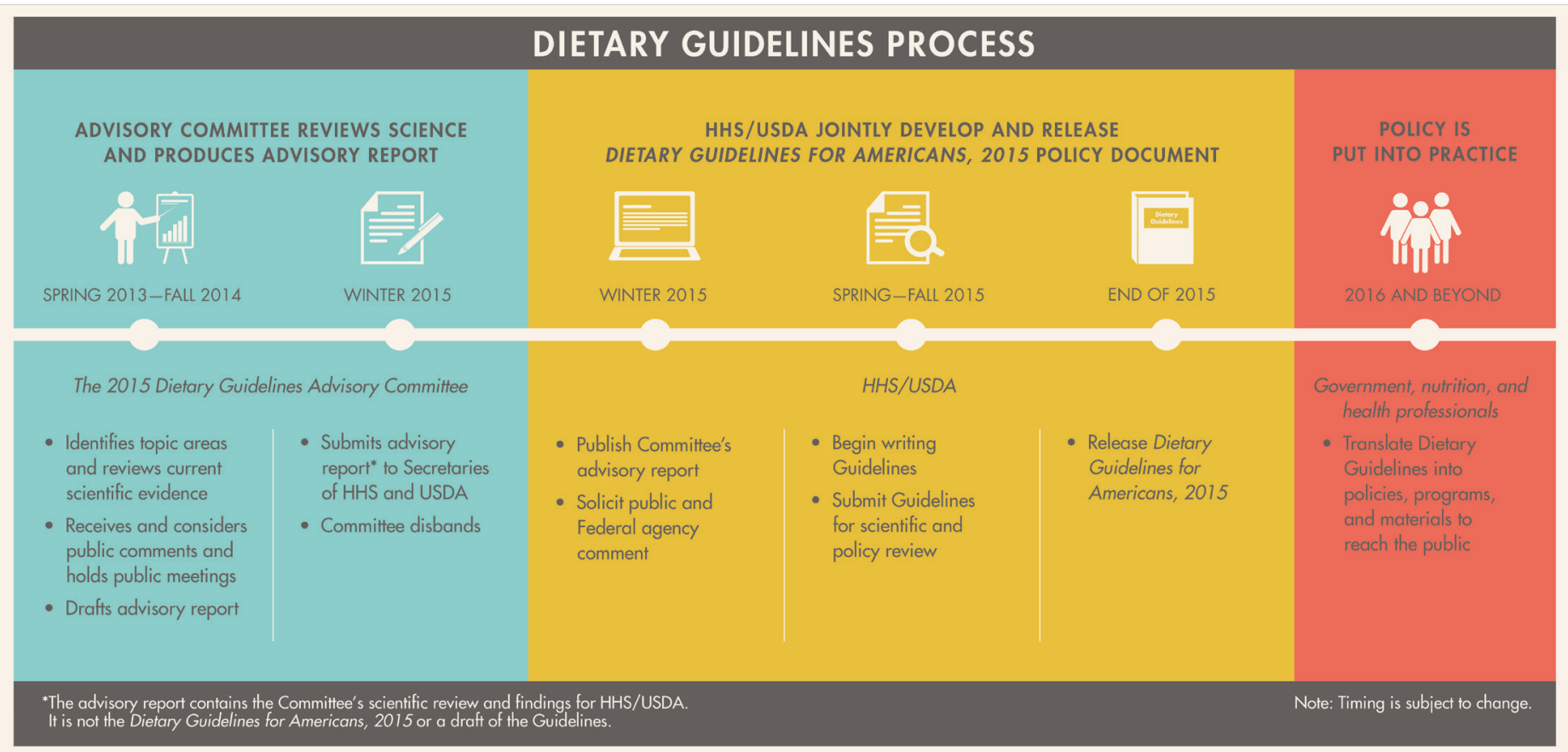

An overview of the 2015 Dietary Guidelines creation process. Source: Office of Disease Prevention and Health Promotion, and US Department of Agriculture, "From Advisory Report to Policy Document: Creating the Dietary Guidelines for Americans, 2015," accessed May 1, 2016, http://health.gov /dietaryguidelines/At-a-Glance-Advisory-Report-to-Policy-Document.pdf.

natural environment and the overall health of the human population. ${ }^{5}$ In July of that same year, President Nixon delivered the Reorganization Plan No. 3, which authorized the creation of an Environmental Protection Agency that would consolidate efforts by different agencies to address sustainability issues into a single agency. ${ }^{6}$ Since then the federal government, with the EPA at the forefront, has worked to address pressing environmental issues such as pollution, resource conservation, pesticide use, and energy efficiency, turning environmental sustainability into an issue of critical national importance. ${ }^{7}$

As environmental sustainability has developed into a central policy issue, agencies like the EPA have published extensive resources to educate the public on the various issues and subsets of sustainability. Today, many of those resources are available online through the EPA's website, where the agency provides an incredible range of information and resources to help members of the public learn about sustainability in general, specific environmental issues like pesticide use or water pollution, and how these issues can affect their personal lives. Given the impact that environmental issues have on individuals and the development of government policies, as evidenced most recently through problems like the Flint water crisis, educational resources that introduce and explain such issues are invaluable.

\section{Dietary Sustainability and the 2015 Scientific Advisory Report}

Within the realm of environmental sustainability, the issue of dietary sustainability has emerged as another critically important component of the broader sustainability challenge. The Food and Agricultural Organization (FAO) recently defined sustainable diets as "diets with low environmental impacts which contribute to food and nutrition security and to healthy

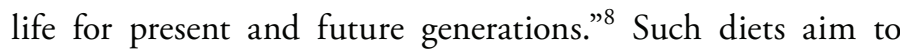
support human health in ways that are also environmentally responsible, such as through a greater reliance on eating local food and reducing consumption of foods that require significant amounts of energy to be produced and transported. ${ }^{9}$ Recent scientific studies have measured the effects of food choices, such as consuming high amounts of meat versus consuming mostly plant-based foods, through indicators like gas emissions and land usage, while others have examined the impacts of environmental degradation, which can result in the loss of food biodiversity and the availability of valuable nutrients, on human health and nutrition. ${ }^{10}$ As with the issue of sustainability in general, the specific problem of dietary sustainability focuses on the intersection between environmental health and human health, with dietary patterns as the key link.

The issue of dietary sustainability came to the forefront of federal policy discussions with the release of the Scientific Advisory Report in February 2015. This report, developed by 
a committee of renowned nutrition and health experts, offered a set of nutrition standards, based on reviews of the most recent scientific literature, that the committee recommended for inclusion in the final guidelines publication. Within the report's chapter on "Food Sustainability and Safety," the committee argued that, although environmental issues had never before been addressed within the guidelines, the strong connections between food consumption and environmental health, and particularly the impact of those connections on long-term food security, warranted the inclusion of a sustainability recommendation. ${ }^{11}$ To encourage a transition toward "less resourceintensive diets," the committee recommended that Americans move toward dietary patterns that favor consumption of vegetables, fruits, legumes, and whole grains while decreasing consumption of some animal-based foods. ${ }^{12}$ These transitions, the committee claimed, would not only address current health epidemics like obesity and diabetes, but would also support environmental health and ensure that healthy, nutritious food would be available for current and future generations. ${ }^{13}$

When the Advisory Report was initially released, reactions to this particular recommendation were passionate and immediate. The US Departments of Agriculture (USDA) and Health and Human Services (HHS) received around 19,000 comments on this recommendation alone, and while a significant majority of those comments were positive, many other expressed fierce opposition to this recommendation. ${ }^{14}$ The USDA and HHS received floods of comments against the recommendation from the general public and from members of Congress, in which they frequently argued that environmental issues were outside the scope of the Dietary Guidelines. ${ }^{15}$ In fact, this recommendation proved so controversial that a provision in the 2016 Consolidated Appropriations Act prevented the Secretary of HHS from continuing with the guidelines unless they focused solely on diet and nutrition. ${ }^{16}$ Eventually, on October sixth, Secretaries Visack and Burwell announced via the USDA blog that, although they felt the issue of environmental sustainability to be an important topic, they determined "because this is a matter of scope, we do not believe that the 2015 DGAs are the appropriate vehicle for this important policy conversation about sustainability." 17 While the Advisory Report's sustainability recommendation may not have made it to the final guidelines, it certainly raised awareness of the topic of dietary sustainability and launched the issue into the national spotlight.

\section{Availability of Government Information on Dietary Sustainability}

Despite the significant attention that this recommendation received in both the government and the media, the federal government currently offers a surprisingly limited amount of information for the general public on the actual topic of food sustainability itself. There are, of course, several resources that get close to the central issue of dietary sustainability, including resources from the USDA on the development of more sustainable agricultural practices and resources from the EPA on reducing food waste. ${ }^{18}$ However, the USDA resources focus on agricultural production, not dietary patterns, while the EPA's resources fail to discuss issues surrounding food sustainability at all, other than in the context of food waste. Though undoubtedly useful in their own right, all of these resources fail to explain or even address the connection between dietary choices, human health, and environmental health, which is ultimately at the heart of dietary sustainability. Without addressing that key issue, the information available on the topic of dietary sustainability is inevitably and woefully incomplete.

Currently, only a very limited number of government resources discuss the role that dietary patterns play in shaping both human and environmental health, and how certain consumption choices can positively or negatively impact both. One of the only exceptions uncovered throughout this research was a webpage created by the Center for Disease Control and Prevention (CDC), yet this resource has several issues that significantly limit its educational value. ${ }^{19}$ Not only is the webpage inaccessible via the topic overviews provided on the CDC website or through links provided in the site index, but several of the links provided at the bottom of this page, which are intended to direct users to more resources, are also broken. Nearly all of those that do work simply redirect to a short seven-year-old podcast with author Michael Pollan. ${ }^{20}$ While this CDC page and the related podcast certainly provide some measure of information, they are hardly adequate for anyone hoping to educate themselves on this issue. Unfortunately, this poorly maintained website is potentially the most that the federal government has provided so far in terms of educational resources.

This overall lack of public-friendly government information undoubtedly impacts the extent to which members of the general public can learn more about this issue. Although this topic has been brought up within the broader context of national policy and could potentially influence its creation in the future, members of the public have no government resources to which they can turn to educate themselves. This absence of resources reflects a missed opportunity on behalf of the government to help the general public engage with and contribute to national dialogues on this topic. While support of specific dietary recommendations is undoubtedly influenced by a variety of additional political and economic factors, it is arguably much more difficult to even have a real discussion on the merits of 


\section{Organic products from far-off lands?}

Organic products from abroad are often cast in an unfavourable light. The reason for this is that transporting them uses up a great deal of energy.

\section{RULE OF THUMB}

Products from overseas produced in the most sustainable way possible may have an acceptable energy balance if there was no costly storage and the goods were transported by ship. As it is hard to find out how the goods were transported, it is best to choose foods that have three specific characteristics: organic, regional, and seasonal. Sometimes, it is not easy to find such products. Make sure then that at least one of the three aspects is covered.

Tips and strategies for sustainable food shopping. Source: German Council for Sustainable Development, "The Sustainable Shopping Basket: A Guide to Better Shopping," November 2013, www.nachhaltigkeitsrat.de/uploads/media/Brochure_Sustainable_Shopping_Basket_01.pdf.

addressing sustainability in the guidelines, let alone effectively argue for its inclusion, if congressional members and members of the public are largely unaware of the issue in the first place. For any meaningful dialogue to take place, those involved must first be aware of the issue and have access to resources that can provide further information.

\section{An International Perspective}

While the US federal government provides a very limited amount of information to help educate the general public on dietary sustainability, the types of resources that other countries and international organizations have developed serve as a valuable model for the resources that US agencies could soon develop. As members of the Advisory Committee noted in their report, the notion of addressing environmental concerns within nutrition guidelines has been widely accepted elsewhere: in countries such as Germany, Brazil, Australia, and several Nordic countries. ${ }^{21}$ The 2013 Australian Dietary Guidelines include an appendix on "Food, nutrition, and environmental sustainability" in which the authors assert, much like the members of the US Advisory Committee, that "health should be considered in sustainable food systems, where the nutritional requirements of the population can be met without placing pressure on natural resources." 22 Similarly, the most recent version of Finland's nutrition recommendations includes a discussion on ways to make food choices that are environmentally sustainable. ${ }^{23}$ Yet in addition, these countries also provide easily accessible educational resources specifically designed to help members of the general public learn about the overall issue of dietary sustainability, as well as the ways in which the issue relates to their personal lives and daily actions. In the recent Nordic Nutrition Recommendations, which included an entire chapter devoted to dietary sustainability, the authors not only succinctly summarized the issue, but also created a series of streamlined tables that clearly list the health and environmental effects of food choices, as a way of informing consumers of the impacts that their food choices have on their physical health and the health of the environment. ${ }^{24}$ Similarly, in addition to addressing environmental sustainability in their dietary guidelines, the German Council for Sustainable Development published a sustainable food shopping guide to help consumers better understand the environmental impact that various foods have, and how they can alter their food choices and shopping habits in a way that is more environmentally sustainable. ${ }^{25}$ This resource includes charts that display the growing seasons for fruits and vegetables, to help consumers purchase foods that can be produced locally and in season, as well as informational guides on what sustainable consumption means, why it is important, and 
how consumers can modify their own food shopping habits to support environmental sustainability.

Even international organizations like the FAO and the United Nations provide a wealth of educational resources on this topic, including guides, educational videos, and much more. For example, the FAO's homepage on "Sustainable Development Goals" provides topical overviews and summaries of different food sustainability issues, links to webpages that discuss individual sustainability goals developed by the UN, and photo galleries that discuss and illustrate various issues and topics related to food sustainability. ${ }^{26}$ In addition, UN sources on sustainability goals and brochures such as "The Lazy Person's Guide to Saving the World" provide basic facts, figure tables on the environmental impacts of various food choices, recent related news stories, and tips and strategies to help general consumers make more sustainable purchases. ${ }^{27}$

The types of easily accessible informational resources that other countries and international organizations have created for the general public serve as valuable models for the resources that US government agencies could also publish. As the Advisory Committee noted several times within its report, "consumer-friendly information that facilitates understanding the environmental impact of different foods" should be widely communicated to the public. ${ }^{28}$ In stark contrast to the limited and poorly maintained resources provided by the US government, the guides, lists, and webpages that other governments and organizations have created present the complex issue of dietary sustainability in an accessible and understandable format. Moreover, these resources not only explain this issue and its importance, but also illustrate how individuals can take action to address it. Ultimately, these resources denote a conscious effort to inform members of the public about an issue that has already shaped, or has the clear potential to shape, government policies that affect the everyday lives of citizens.

\section{Conclusion}

The fierce controversy surrounding the sustainability recommendation of the 2015 Advisory Report revealed an overall lack of resources on dietary sustainability that the US government has produced for the general public. Yet the increased attention that the report generated on this issue has also created a perfect opportunity for government agencies to address this absence. Government informational resources provide an invaluable contribution to the general public's education on social and political issues that affect both government policy and their personal everyday lives. While the US has yet to incorporate sustainability into its Dietary Guidelines and may not do so for some time, the topic has clearly become important within the scientific and broader international community. Now, with the Advisory Report, this issue has directly impacted policy discourse in the US government as well. Though the role of diet represents only one factor within the broader realm of environmental sustainability, it is a critical factor, and one that has directly confronted our current understanding of the connections between human and environmental health and how society can support both in tandem. Just as federal agencies like the EPA have created resources on other sustainability issues that have influenced government policy, the time has come to develop more resources that address this growing issue of dietary sustainability. The availability of informational resources would create opportunities for informed and thoughtful discussions on this issue to take place, ultimately providing the foundation upon which our society can continue to face the environmental and health challenges of the twenty-first century.

Sarah Klimek (sklimek@umail.iu.edu), MLS Candidate, May 2017, Indiana University, Bloomington.

\section{References}

1. Allison Aubrey, "Will the Dietary Guidelines Consider the Planet? The Fight is On," The Salt (blog), National Public Radio, February 26, 2015, www.npr.org/sections /thesalt/2015/02/26/389276051/will-the-dietary-guide lines-consider-the-planet-the-fight-is-on.

2. Dietary Guidelines Advisory Committee, "Part D. Chapter 5: Food Sustainability and Safety," in Scientific Report of the 2015 Dietary Guidelines Advisory Committee, 1, http:// health.gov/dietaryguidelines/2015-scientific-report /PDFs/10-Part-D-Chapter-5.pdf.

3. National Research Council, Sustainability in the U.S. EPA (Washington, DC: National Academies Press, 2011), 16, www.nap.edu/read/13152/chapter/2.

4. National Environmental Policy Act of 1969, Pub. L. No. 91-90, 83 Stat. 852 (1969).

5. Ibid.

6. Reorganization Plan No 3 of 1970, 35 Fed. Reg. 194, 15623 (July 9, 1970).

7. National Research Council, Sustainability in the U.S. EPA, 17-18.

8. Food and Agricultural Organization of the United Nations, Biodiversity and Sustainable Diets: United Against Hunger (Rome: FAO Headquarters, 2010), ix, www.fao .org/ag/humannutrition/28506-0efe4aed57af34e2d bb8dc578d465df8b.pdf. 
9. Institute of Medicine, Sustainable Diets: Food for Healthy People and a Healthy Planet: Workshop Summary (Washington, DC: The National Academies Press, 2014), 14-15, www.nap.edu/read/18578/chapter/1.

10. Advisory Committee, "Food Sustainability and Safety," 10-11; Institute of Medicine, Sustainable Diets, 13-14.

11. Advisory Committee, "Food Sustainability and Safety," 1.

12. Advisory Committee, "Food Sustainability and Safety," 1-2; Institute of Medicine, Sustainable Diets, 9-16.

13. Advisory Committee, "Food Sustainability and Safety," 12-14.

14. Hearing to Review the Development of the 2015 Dietary Guidelines for Americans: Hearing Before the Committee on Agriculture, 114th Cong. 20 (2015) (statement of Sylvia Burwell, United States Secretary of Health and Human Services).

15. Vicky Hartzler and Mike Conaway to Secretary Tom Vilsack and Secretary Sylvia Burwell, March 31, 2015, http:// agriculture.house.gov/uploadedfiles/ag_dietaryguide lineslettertosecsvilsackburwell.pdf; Domestic Social Policy Division, Cong. Research Serv., R44360, Dietary Guidelines for Americans: Frequently Asked Questions, at 7-8 (2016).

16. Consolidated Appropriations Act, Pub. L. No. 114-113, 116 Stat. 2242 (2015).

17. Thomas Vilsack and Sylvia Burwell, "2015 Dietary Guidelines: Giving You the Tools You Need to Make Healthy Choices," USDA Blog (blog), October 6, 2015, http://blogs.usda.gov/2015/10/06/2015-dietary-guide lines-giving-you-the-tools-you-need-to-make-healthy -choices/.

18. “Organic Agriculture," US Department of Agriculture, last modified June 2, 2016, www.usda.gov/wps/portal/usda /usdahome?navid=organic-agriculture; "Learn about Greener Living," Environmental Protection Agency, accessed April 30, 2016, www.epa.gov/learn-issues/learn -about-greener-living.
19. "Sustainable Food," Center for Disease Control and Prevention, last modified April 3, 2012, www.cdc.gov /sustainability/food/.

20. Center for Disease Control and Prevention, "Feeding Health: Thoughts on Healthy Food for a Healthy Planet," CDC podcast with Michael Pollan, 11:17, August 18, 2009, www2c.cdc.gov/podcasts/player.asp? $\mathrm{f}=1262141$.

21. Advisory Committee, "Food Sustainability and Safety," 3.

22. National Health and Medical Research Council, Australian Dietary Guidelines: Providing the Scientific Evidence for Healthier Australian Diets (Canberra: National Health and Medical Research Council, 2013), 131, www.eat forhealth.gov.au/sites/default/files/files/the_guidelines /n55_australian_dietary_guidelines.pdf.

23. "Finnish Nutrition Recommendations 2014," National Nutrition Council, accessed April 30, 2016, www.ravitse musneuvottelukunta.fi/portal/en/nutrition+recommen dations/.

24. Nordic Council of Ministers, Nordic Nutrition Recommendations 2012: Integrating Nutrition and Physical Activity (Copenhagen, 2014), 148-52, norden.diva-portal.org /smash/get/diva2:704251/FULLTEXT01.pdf.

25. German Council for Sustainable Development, "The Sustainable Shopping Basket: A Guide to Better Shopping," November 2013, www.nachhaltigkeitsrat.de/uploads /media/Brochure_Sustainable_Shopping_Basket_01 .pdf, 16.

26. "Sustainable Food Development Goals," Food and Agriculture Organization of the United Nations, 2016, www .fao.org/sustainable-development-goals/home/en/.

27. "Goal12:EnsureSustainableConsumptionandProduction Patterns," United Nations, accessed April 30, 2016, www .un.org/sustainabledevelopment/sustainable-consump tion-production/; "The Lazy Person's Guide to Saving the World," United Nations, accessed April 30, 2016, www .un.org/sustainabledevelopment/takeaction/.

28. Advisory Committee, "Food Sustainability and Safety," 10. 